\title{
ASPECTOS RELACIONADOS A ADESÃO AO TRATAMENTO DE USUÁRIOS DE UM CAPS AD DO INTERIOR DA BAHIA SOB A ÓTICA DOS PROFISSIONAIS
}

\section{Iandra Sara dos Santos Ferreira ${ }^{1}$; Sinara de Lima Souza ${ }^{2}$}

1. Bolsista PIBIC/FAPESB, Graduanda em Enfermagem, Universidade Estadual de Feira de Santana, e-mail: iandra.sara4@gmail.com

2. Orientador, Departamento de Saúde, Universidade Estadual de Feira de Santana, e-mail: sinarals@uefs.br

PALAVRAS-CHAVE: Adesão, CAPS, profissionais de saúde

\section{INTRODUÇÃO}

O consumo de substâncias lícitas e ilícitas não é um assunto recente. Desde os primórdios da humanidade relatos apontam para o uso de substâncias psicoativas (SPAs) com várias finalidades, dentre elas, a medicinal e a recreativa, sendo consumida das mais diferenciadas formas. Contudo, o limiar entre o uso e o abuso é bastante tênue e, a dependência química se constitui em uma situação na qual o indivíduo estabeleceu uma relação com a SPA, na qual se tornou refém da mesma.

Os Centros de Atenção Psicossocial álcool e drogas (CAPS ad) que se constituem como serviços de atenção psicossocial que devem ofertar atendimentos capazes de responder às particularidades de cada sujeito, dos familiares e da comunidade em seu entorno, trabalhando na lógica de Redução de Danos (RD) e sendo apoiados por outras práticas de atenção comunitária (BRASIL, 2003).

Um fator preditivo que contribui para a eficácia do tratamento de transtornos mentais é a adesão ao tratamento. A adesão é imprescindível para o gerenciamento desse transtorno, e depende dela o sucesso da terapêutica proposta, a minimização dos sinais e sintomas, a remissão do transtorno, a redução de possíveis doenças e agravos, a motivação para a reabilitação, prevenção de lapsos e recaídas e a reinserção social (MONTEIRO, et. al, 2011)

$\mathrm{Na}$ condição de estudante do curso de graduação em Enfermagem, saliento a importância de considerar como os profissionais do CAPS ad visualizam a adesão ao projeto terapêutico singular, tido por alguns como sinônimo de tratamento. Diante disso surgiu o seguinte questionamento: Qual a percepção dos profissionais de um CAPS ad do interior da Bahia sobre a adesão às terapêuticas oferecidas?

Nesta perspectiva este estudo teve como objetivo analisar os fatores relacionados a adesão às terapêuticas oferecidas aos usuários de um CAPS AD do interior da Bahia sob a ótica dos profissionais.

\section{METODOLOGIA}

Trata-se de um estudo qualitativo, descritivo. O campo do estudo foi um CAPS ad do interior da Bahia. A técnicas de coleta adotada foi a entrevista semiestruturada. Os participantes foram os profissionais do CAPS ad. Os dados dessa pesquisa são oriundos do banco de dados do projeto de pesquisa e extensão aprovado pela resolução CONSEPE N. ${ }^{\circ}$ 43/2012 intitulado "Perfil sociodemográfico e aspectos relacionados à adesão ao tratamento de pacientes de um CAPS ad do interior da Bahia". Análise de dados foi através da análise de conteúdo temática, na qual foram seguidas as etapas sugeridas por Gomes (2007, p100): transcrição das entrevistas, leitura compreensiva do material selecionado, exploração do material, elaboração e síntese interpretativa. A partir desse processo, chegamos à categorização dos dados, a fim de realizar a interpretação propriamente dita dos achados do estudo. No tocante aos critérios éticos, o projeto foi submetido à apreciação do Comitê de Ética e Pesquisa da Universidade Estadual de Feira de Santana- BA, tendo sido registrado e aprovado sob o protocolo $n .^{\circ} 114 / 2011$ (CAAE $\mathrm{N}^{\circ}$ 0119.059.000-11).

\section{RESULTADOS E DISCUSSÃO}


A pesquisa contou com 13 participantes, membros da equipe multidisciplinar do CAPS AD, sendo 9 do sexo feminino e 4 do sexo masculino, com idade entre 22 e 72 anos. Em relação ao tempo de atuação, havia profissionais com 2 meses de atuação até 8 anos no serviço.

Esse estudo aborda os desafios encontrados pelos usuários na visão dos profissionais do serviço, para adesão as terapêuticas oferecidas. Foram elaboradas três categorias que revelaram como se deu a procura ao serviço, as dificuldades para adesão ao tratamento e os fatores influenciadores para o abandono.

\section{Procura ao serviço}

Segundo os participantes do estudo, a busca pelo serviço é percebida como um processo difícil, para a qual se faz necessário o reconhecimento pelo indivíduo da sua condição de dependente químico que necessita de tratamento.

[...] precisa antes de qualquer coisa de reconhecer a necessidade de um tratamento, reconhecer em si a dependência química, né? que é muito difícil [...] (P6 F)

A fala trazida pelo profissional acerca do processo de reconhecimento da dependência química e necessidade de tratamento como algo difícil remetem à necessidade da existência de uma equipe qualificada para o atendimento a esta clientela, visto que, possui especificidades que divergem de outros grupos. Os achados do estudo de Malvezzi et al. (2016) revelaram também que a vontade em tratar e a compreensão do paciente sobre seu quadro clinico, enquanto uma pessoa que precisa de ajuda, faz diferença no tratamento e contribui significativamente para a adesão.

Outro elemento que emergiu entre as falas dos profissionais participantes, foi a respeito do preconceito dos usuários sobre sua condição de dependente:

[...] preconceito que as pessoas ainda têm em buscar ajuda, de se reconhecer enquanto uma pessoa que tem dependência química[...] (P13 F)

Historicamente indivíduo usuário de drogas carrega um estigma, uma rotulação que propõe que a droga e quem a usa, está associada a uma pessoa fraca, sem força de vontade, marginal, preta, favelada, gente ruim, pobre, vagabundo, que será viciado para sempre e eu este é um caminho sem volta. Tais rotulações refletem diretamente na resistência para buscar o serviço. Pois, as pessoas acabam, introjetando tais colocações e passam a desacreditar na possibilidade de superação. Tanto o descrédito em relação à possibilidade de superação das dificuldades quanto o não reconhecimento da dependência química, adiam a compreensão do CAPSAD enquanto espaço de acolhimento as individualidades e suporte terapêutico.

\section{Dificuldades para adesão}

Os elementos que emergiram como dificultadores para o processo de adesão ao tratamento, foram a família, abstinência/fissura, os amigos e questões socioeconômicas.

Primeira dificuldade encontrada, muitas vezes é o comprometimento [...] ou vem com a vontade maior da família e não por vontade própria, isso é um dos dificultadores, porque primeiro você tem que querer, e se a vontade não for maior do que todas essas outras coisas, com certeza o tratamento não vai poder dar continuidade. (P11 F)

Quando a maior vontade para o tratamento do usuário vem do meio externo como no caso da família, configura-se como um elemento dificultador para adesão, pois, a motivação, deve sobretudo partir do usuário. Discutindo sobre motivação Ferreira et al. (2015) aborda que se o paciente procura o serviço pela família ou pelos amigos, a adesão vai estar ligada ao insucesso, e é um desafio para os profissionais porque as mudanças e o comprometimento necessário para a efetividade da terapêutica precisa partir do usuário, e se ele chega ao serviço porque a família quis, automaticamente não acontecerão as mudanças necessárias.

A abstinência e a fissura também foram reconhecidas pelos profissionais como elementos dificultadores para o processo de adesão, como retratado a seguir: 
Então, acho que essa questão da fissura, principalmente no início da crise de abstinência, né? quando resolve deixar de usar a droga, que é muito difícil por conta dos sintomas... (P1 F)

Marques e Seibel (2000) ao discutirem sobre craving ou "fissura" descrevem esse fenômeno como um estado em que o indivíduo tem a extrema necessidade, ou desejo intenso de usar a droga e que pode ocorrer momentos após o uso, ou após períodos prolongados sem a droga, em abstinência. A família assim como os amigos é mencionada como pessoas que dificultam o processo de adesão:

Influência de amigos, falta de apoio da família... a fissura que muitas vezes é mais forte do que o sujeito consegue lidar. (P6 F)

Relações conflituosas tendem a gerar baixa adesão ao tratamento, dessa forma, os estudos de Silva, Guimarães e Salles (2015) trazem que a desestrutura familiar permeada por conflitos familiares tendem a se constituírem como fatores de risco para a recaída, uma vez que, cobranças, brigas e discussões com o usuário de substâncias psicoativas o fazem buscar na droga um meio pelo qual ele possa se distanciar e fugir de tais situações.

\section{Os elementos que influenciam para o abandono}

Dentre os elementos que surgiram com influência para o abandono destacaram-se, a dependência de um remédio prescrito, a recaída como possibilidade, amigos, família, a fissura, baixa autoestima, voltar a trabalhar e separações.

Experiência que ele ainda acha que pode deixar de usar a medicação... quando eles chegam ao ponto que acham que não conseguem mais deixar. (P3 F)

A fala acima aponta para uma situação na qual o usuário do serviço deixará de ser dependente da droga ilícita para se tornar dependente dos medicamentos prescritos na terapêutica. Corroborando com esse achado, o estudo de Ferreira et al. (2015) traz que a medicação é um grande preditor para a adesão, mas nem só por meio dela é possível alcançar o sucesso na terapêutica. É importante esclarecer que a medicação é um componente da terapêutica, mas não o único. Pois, ao supervalorizar a medicação e não aderir às outras modalidades terapêuticas, pode ser que com o passar do tempo, ocorra também a desmotivação para a continuidade. Com a suspensão abrupta do medicamento surge a possibilidade da ocorrência da síndrome de abstinência

[...] muitos ficam na abstinência e depois tem a recaída, e nessa recaída mesmo que eles abandonam o tratamento. (P5, F)

Para Czarnobay et al. (2015) a recaída faz parte do tratamento, o meio em que o usuário transita, o não reconhecimento de sua impotência perante o vício, e a dificuldade em lidar com frustações podem favorecer seu acontecimento. Atrelada a essa possibilidade, outras situações também corroboram:

Desemprego e baixa autoestima. (P7 F)

A família, os amigos, a fissura, a condição de desemprego e a baixa autoestima são trazidos acima com questões que contribuem para o abandono ao tratamento. Estudos realizados por Argolo e Araújo (2004) revelaram que a condição de desemprego pode levar a depressão e a baixa autoestima, assim como mencionado na fala acima.As relações afetivas aparecem na fala dos entrevistados com um elemento preditor para o abandono:

[...]separações, podem estar influenciando na recaída ou abandono do tratamento $[\ldots](13 \mathrm{~F})$

A fala acima remete para o impacto emocional de relações interrompidas. Como já visto, muitas situações podem influenciar a recaída. O retorno ao uso de drogas pode ser motivado pela regulação afetiva sendo ela positiva ou negativa. Tal fato pode ser explicado pela dificuldade que o usuário tem, em lidar com os sentimentos pois não os consegue manejar e controlar seu estado emocional (CZARNOBAY et al. 2015). 


\section{CONSIDERAÇÕES FINAIS}

No presente estudo foi percebido que a chegada do usuário ao serviço é vista pelos profissionais como um processo difícil, que requer o reconhecimento do usuário quanto à necessidade de ajuda e da sua condição de dependente químico, e da existência de preconceito por parte dos usuários para a busca do tratamento, tendo em vista a construção social sobre o usuário de drogas. Na segunda categoria, a família, os amigos, a fissura, e as condições socioeconômicas configuraram-se como elementos que dificultam a adesão. Na terceira e última categoria sobre os elementos que contribuem para o abandono, destacaram-se a recaída, o desemprego, a baixa autoestima, o uso da medicação e relações afetivas desconstruídas. Considerando que os objetivos da pesquisa foram alcançados, como sugestão para pesquisas futuras, se faz necessário um projeto de intervenção no serviço com a equipe multidisciplinar, visando sensibiliza-los sobre a proposta do CAPS AD, no que compete à Política de Redução Danos preconizada pelo Ministério da Saúde, para melhor abordagem e assistência ao usuário, considerando que a precarização do vínculo empregatício provoca uma alta rotatividade da equipe.

\section{REFERÊNCIAS}

ARGOLO, João Carlos Tenório; ARAUJO, Maria Arlete Duarte. O impacto do desemprego sobre o bem-estar psicológico dos trabalhadores da cidade de Natal. Rev. adm. contemp., Curitiba, v. 8, n. 4, p. 161-182, Dec. 2004

BRASIL. Ministério da Saúde. A Política do Ministério da Saúde para atenção integral a usuários de álcool e outras drogas - Brasília: Ministério da Saúde, 2003.

BRASIL. MINISTÉRIO DA SAÚDE. Resolução no 466 de 12 de dezembro de 2012 do Conselho Nacional de Saúde. Brasília, DF: Ministério da Saúde, 2012.

CZARNOBAY, Juliana et al. Determinantes intra e interpessoais percebidos pela família como causa da recaída do dependente químico. Rev Min Enferm. v. 19, n. 2, p. 93-99. abr/jun, 2015.

FERREIRA, Alice Cristina Zerwes et. al. Fatores que interferem na adesão ao tratamento de dependência química: percepção de profissionais de saúde. Revista Mine de Enferm. v.19, n.2, p. 150-156, 2015.

GOMES, R. Análise e interpretação de dados em pesquisa qualitativa. In: MINAYO, M. C. S. (Org.). Pesquisa social: teoria, método e criatividade. 25. ed. revista e atualizada. Petrópolis: Vozes, 2007. p. 79.

MALVEZZI, Cilene Despontin et al. Adesão ao tratamento pela equipe de um serviço de saúde mental: estudo exploratório.Online Brazilian Journal of Nursing, [S.1.], v. 15, n.2, p. 177-187, jun. 2016.

MARQUES, A. C., SEIBEL, S. D. O Craving. In: SEIBEL, S. D; TOSCANO Jr., A. Dependência de Drogas. São Paulo: Atheneu, 2000, 239-246.

MONTEIRO, CFS, et al. Perfil sociodemográfico e adesão ao tratamento de dependentes de álcool em CAPSad do Piauí. Esc Anna Nery Rev Enferm. 2011;15(1):90-5.

SILVA, Meire Luci da; GUIMARÃES, Camila Ferreira; SALLES, Daiane Bernardoni. Fatores de risco e proteção à recaída na percepção de usuários de substâncias psicoativas. Rev. Rene. v. 15, n. 6, p. 1007-15, nov-dez, 2014. 